\title{
EDITORIAL
}

FRANCISCO DÍAZ

Editor revista ARQ

Profesor, Pontificia Universidad Católica de Chile

Santiago, Chile

\section{LOOKING DOWN}

On September 2, 2015 the world was shocked by the image of Aylan Kurdi, a 3-year-old Syrian child that was found drowned on Turkey's shoreline. Along with his family and many of their countrymen, the child was escaping the civil war in his homeland when the boat he was travelling sank while crossing the Mediterranean. His journey to a war-free land ended tragically. The image of his body lying on the beach, looking down, on the edge between the sea and the land, remains engraved in our memories reminding us that the land is much more than a mere material condition: it is also an abstract construct made of local laws, international treaties, private properties and market values that, despite being invisible, are so real that drive human beings -and even capital- to flow in search of better conditions.

On January 31, 2016 a regrettable reenactment of the scene by artist Ai Wei Wei -who photographed himself lying on the shores of Lesbos in Greece looking down in the same position as Kurdi- not only came to remind us of the obvious inability of art to represent these phenomena, but also how the circulation of images trivializes reflection upon them, up to the point that talking about this scene now seems obsolete.

But this obsolescence is only apparent. While this image is already archived as news from one year ago, it is still fresh as reflection material, especially in our field. For if architectural knowledge comprises the study and problematization of the land, as well as the provision of spaces to live in, the fact that someone lost his life trying to reach a new land to inhabit could perfectly become an architectural concern.

Of course this issue of ARQ cannot answer all the questions that this scene leaves behind. However, aware of our mission of promoting new territories of knowledge, we have focused on presenting the architectural quests for new lands, either in projects, essays or research, publishing a range of readings and questionings on a subject that, despite being ancient, is far from exhausted.

From debates on the land-value (by Martin, Moore \& Schindler, and also by Montealegre) to conceptualizations about it (by Celedón and by Torrent); from territorial disputes (in Weizman and in Jaque) to interventions on the territory (by González and by Design Earth); from strategies to expand public land (by Carreño \& Sartori) to the possibility of publicizing different lands (by Herzog \& de Meuron); from 
subsoil as a territory of geopolitical disputes (in Belanger) to subsoil as a storage of ancient wisdom (in Jorquera \& Soto); from the ground transformed to create a new program (by Mayoral \& Murray) to the ground lifted to conceive a new typology (by OMA). All of these approaches open up a world of possibilities that expand the classic understanding of the land as architectural ground -be it structural, existential or symbolic.

For if it is logical to think that 'land' does not mean the same for a farmer than for a topographer, a geographer, an archaeologist, a real estate broker or a geologist, it would be equally logical to assume that the multiple ways in which architecture develops nowadays extend the notions of land far beyond the mere physical support meant for receiving a building. Perhaps this is the reason why concepts such as 'territory', 'platforms', 'fields' or 'groundings' have become part of our daily conversations given that, if architecture is located on a land, then there will be as many notions of it as ways of understanding architecture.

Still, new challenges come up every day. Today, for instance, when the promise of a globalized world is clashing against people willing to defend 'their land' from the presence of those many others who have left their own, it seems necessary to ask ourselves again -from the different points of view that architecture can offer- not only for what land means, but also for what it implies. What new types of land can architecture propose to these realities? How do we imagine these lands where not only capital but also people -independently of their origins- are accepted and welcomed? It is very likely that the answers to these questions can't be found in this issue of ARQ, but we have cared about bringing together those who -with less opportunism than Ai Wei Wei- are looking down with many other questions and concerns that, hopefully, will end up opening up new territories for architecture. ARQ

\footnotetext{
* Note of the editor. In Spanish, the word 'suelo' has three main meanings: 'land', 'ground' and 'soil'. For this issue of ARQ, we have chosen to translate it as 'land' since this word, in some way, encompasses all the other meanings. However, the entries selected for this issue refer to -or work with-any of the aforementioned concepts.
} 